\title{
Foreword to Opinion Pieces
}

A year ago, when Place Branding was launched, we decided to run an extended 'OpEd' as part of the first issue - a collection of short comments and observations from some of the members of our Editorial Board on the theme 'where is place branding heading?'.

For the first issue of the second volume of the journal it seems appropriate to take that measurement again, and the following pieces are the responses of some members of the Board to the question 'How has place branding developed during the year that Place Branding has been in publication?'.

The responses speak for themselves, but if ever there was any doubt in any of our minds about the emergence of this important field, that doubt must surely now have receded. The race is now on to ensure that governments of countries, cities and regions fully understand the complexity of place branding, the patience and wisdom required to plan and implement it and the fact that if places really want to change their reputations, they really have to change. Communications programmes simply will not do it.

As Socrates said, 'The way to acquire a good reputation is to endeavour to be what you desire to appear.'

\author{
Simon Anholt \\ Managing Editor
}

